\title{
Determinators of Schedule Delay Risk of the Highway Project in Vietnam: Based On the SEM model
}

\author{
Honganh VU', a , Jianqiong WANG ${ }^{1, b}$, Jicai LIU1 ${ }^{1}$, Lianxing $\mathrm{MIN}^{2, \mathrm{c}}$, Syhung MAI \\ ${ }^{1}$ School of Economics and Management, Southwest Jiaotong University, Chengdu 610031, China \\ ${ }^{2}$ School of Management, Chengdu University of Traditional Chinese Medicine, Chengdu 611137, \\ China \\ a584335443@qq.com, bqiongsi007@126.com, md3318@163.com
}

\begin{abstract}
Keywords: Construction Progress, Schedule Delays, Structural Equation Model, Risk Evaluation
Abstract. With the economic development of Vietnam in recent years, the highway construction develops rapidly and brings the international construction companies a good opportunity, but the phenomenon of schedule delays has a serious impact on the project investment efficiency, cost and reputation. In this paper, on the basis of former study and combining with interviews of Vietnam expert, we investigated the influential factors of highway construction schedule in Vietnam by the questionnaire survey in 2014, and evaluated the mutual influence of the above factors by using structural equation model (SEM). The empirical results showed that the 7 factors had significant impacts on the construction schedule delay. Finally, we propose the specific management suggestions to improve the international construction companies' ability of risk management when participating in the highway project contract in Vietnam.
\end{abstract}

\section{Introduction}

In recent years, along with the rapid development of Vietnam's national economy, the highway construction develops rapidly, the Vietnamese government absorbs domestic and foreign funds to participate in construction with preferential policies and different ways of investment by modes of BOT, BTO, BT and PPP to accelerate the development of highway construction. Vietnamese Prime Minister Nguyen Tan Dung assert a claim to plan to build $2500 \mathrm{~km}$ highway before 2020 by using the diversified funds investment, but at the moment, according to 2014 adjustment planning put forward by Vietnam's transport ministry, "Currently because of extension of Vietnam highway construction, 1800 kilometers can only be built by 2020." There are a lot of projects, which belong to the international cooperation projects, but project delay will bring economic loss to the enterprise, affect investment enthusiasm, and damage the expected revenue of the highway construction. If risk factors of project delays can be effectively identified before construction, the delays risk can be controlled effectively and reduced to minimum. Therefore, it is necessary to research the influence factors of delays risk, to help the relevant government department and foreign enterprises to take corresponding measures, to improve the level of project management, and to promote the development of highway construction in Vietnam, which has important practical significance.

\section{Theory Analysis}

Construction delay, which is often encountered in engineering constructions, is defined by scholars as the completion date of the project implementation being later than the planning date which leads to the schedule delays of the whole contract [1]. Scholars generally believe that the project construction schedule delay is caused by a variety of factors, and discuss them from different angles. The owner management ability, organization and team members and external environment are the main reasons of schedule delays in construction period [2]. From the perspective of different stakeholders and the environment, risks are focused on in China, and the owner, survey, design and the government have to be strict management from the feasibility stage, in order to solve the potential 
risks that may be encountered in the construction stage [3]. Through the questionnaire survey combined with expert interviews, the safety and quality, completion of previous projects, environment, management and technology, resources, organization, experience, project type and capital are the key success factors of the contractor [4]. Scholars identify different risk factors, at the same time use the quantitative methods to evaluate the influence degree. A risk evaluation model of the bidding phase of China highway project is established, which uses analytic hierarchy process for empirical analysis, and the results show that macro factors such as policy and financing risk and microscopic factors such as technology and resources have the largest effects [5]. Through a large number of investigation of Indian experts, 93 kinds of potential risk factors are divided into two groups and nine classes, which uses fuzzy analytic hierarchy process [6]. In the United Arab Emirates (UAE) highway engineering project evaluation, 33 risk factors are pointed out that, through the relative important index (RII), key risk affecting highway are pointed out, which includes low planning efficiency, unexpected underground facilities, the design quality and integrity, slow approval and land acquisition delay [7]. In practice, due to the conditions of different countries and regions, the same factors in different stages of practice, the factors causing delays is also different, which need discusses respectively, so the condition in Vietnam is no exception. Empirical research on delay risk factors of large engineering project construction is carried on in Vietnam, which summarizes 59 specific factors and 7 main factors including financier, owner, contractor, consultant, project attributes, coordination and environment [8]. 87 Vietnamese experts are interviewed combining with questionnaire survey and the results show that there are seven main factors that affect the construction progress, including financial ability, management ability, design, and lack of constraints, market and labor [9]. The construction progress is one of the main reasons that influence project delays, and project delays of Vietnam construction mainly exist in owner management, staff ability and external environment according to questionnaire survey [10].

To sum up, current study has the following characteristics and disadvantages: (1) The risk factors and their impacts, such as the owner, contractor, supervision, survey and design, environment changes and policy changes, are recognized and confirmed in the literature, but there are few researches discuss them in together. (2) In the discussion of related influential factors of project delays, some potential variables are involved and cannot be directly measured, such as the owner risk, contractor, etc., but a lot of measurement error must occur when observation measurement is used to make indirect measurement. Furthermore, there is also a strong correlation between risk factors and the interaction is complex, and the main research methods depict the influence relationship insufficiently. Therefore, SEM model are used to evaluate the influence of various factors, in order to identify core factors more effectively, then put forward the corresponding advice about risk management of construction progress.

\section{Questionnaire Design and Data Collection}

Variable indicator design

Result variable

Schedule delays of construction projects are not only cause the time delay and opportunity cost, but also make the time for owner of putting the project in use is delay, which will increase the contractor's cost, reduce investment profit and credibility [11-12]. Therefore, this article use time delay, cost increase and credibility reduce to measure the variable of schedule delay rise.

Condition variable

This paper analyzes the factors influence on construction schedule delays in Vietnam highway construction phase. This article refers to questionnaire of Long et al. (2004), Le-Hoai et al. (2008), Al- 
zahrani and Emsley (2013), etc. and the suggestions by 9 Vietnamese experts have more 20 years of experience in engineering construction. total of 59 indexes are put forward.

\section{Data collection}

The questionnaire is implemented in multiple highway projects in Vietnam, through the ministry of communications and general contractors in 2014. The investigation altogether provides questionnaire 350 , the actual recovery of 283 copies and a total of 246 valid questionnaire responses received after eliminating the questionnaire with data missing. Scale uses Likert5 level measurement. The response rate from owners, contractors, subcontractor, Supervision unit and Survey and design unit is $20.19 \%, 28.05 \%, 13.97 \%, 13.65 \%, 24.14 \%$ respectively. Regarding number of years involved in construction, $22.24 \%$ of respondents have less than or equal to 3 years, $38.71 \%$ of those have between 4 and 6 years, 23.63\% of those have between 7 and 10 years and $15.42 \%$ of those have 10 years or more. It would be better if the percentage of respondents whose experiences are 10 years or more can be increased.

\section{Data Analysis}

\section{Exploratory factor analysis}

Test the premise variables data

The inspection results of KMO and Bartlett's Test show that KMO value of 0.800 that is greater than the standard value (0.6) indicates variables are suit to factor analysis, Bartlett's Test of Sphericity approx. Chi-square value of 2747.649 and significant level p of 0.000 (sig.<0.05) indicate strong correlation between variables is suitable for factor analysis. As the results showed by exploratory factor analysis and the criterion of 0.6 , the factor index load can be divided into 8 categories (see the table 1). The correlation of not shown other variables and factors are not suitable for research, therefore, in the next step those factors are ruled out.

Table 1. Factors causing construction schedule delays

\begin{tabular}{cccc}
\hline Hypothesis & $\begin{array}{c}\text { Retention } \\
\text { index }\end{array}$ & Latent variable & $\begin{array}{c}\text { Serial } \\
\text { number }\end{array}$ \\
\hline H1 & 2 & Owner fiscal ability factor & OFA \\
H2 & 3 & Management ability of project management unit & MAP \\
H3 & 3 & Contractor fiscal capacity factor & CFC \\
H4 & 3 & Environment risk factor & EC \\
H5 & 3 & Selection and management of subcontractor factor & SMS \\
H6 & 3 & Supervision unit ability factor & SA \\
H7 & 4 & Survey and design unit ability factor & SDA \\
H8 & 3 & Policy imperfection factor & PI \\
\hline
\end{tabular}

Test result variables data

Use the same method to process result variables, the results show that KMO value of 0.708 is greater than the standard value (0.5), which indicates variable is suitable for factor analysis. Bartlett's Test of Sphericity approx. Chi-square value of 800.73 and significant level p of 0.000 (sig.< 0.05 ) indicate strong correlation between variables is suitable for factor analysis. Eventually Time delay, Cost increase, and Credibility reduce extract a factor, namely the construction schedule (CS).

Measurement model test

The suitability test of measurement contains the reliability and validity test. Confirmatory factor analysis results show that the factor loading value of every latent variable is greater than 0.7 , which means good internal consistency. As seen from table 2, composite reliability value and Cronbach's 
alpha of each latent variable is above 0.7 . So the model satisfies the test requirement of reliability. As shown in table 2, all indicators load value is greater than 0.7 and the AVE (Average Variance Extracted) is greater than 0.5 , which are up to the criteria of convergent validity test.

Table 2. Latent variable, composite reliability, total variance, Cronbach's alpha and AVE

\begin{tabular}{lccc}
\hline \multicolumn{1}{c}{ Constructs } & $\begin{array}{c}\text { Composite } \\
\text { reliability }\end{array}$ & Cronbach's alpha & AVE \\
\hline EC & 0.800 & 0.797 & 0.668 \\
MAP & 0.787 & 0.785 & 0.552 \\
OFA & 0.785 & 0.780 & 0.549 \\
SMS & 0.803 & 0.803 & 0.577 \\
SDA & 0.817 & 0.816 & 0.599 \\
CFC & 0.842 & 0.839 & 0.640 \\
SA & 0.893 & 0.889 & 0.736 \\
PI & 0.896 & 0.906 & 0.685 \\
CS & 0.942 & 0.937 & 0.845 \\
\hline
\end{tabular}

Furtherly, we conducted the discriminant validity test by AVE. As is shown in table 3, each AVE between latent variables is higher than the square of the correlation coefficient between its latent variable and other potential variables in the model, which means it passed the test .

Table 3. The square of AVE and correlation coefficients between latent variables

\begin{tabular}{lccccccccc}
\hline & CS & EC & MAP & OFA & SMS & SDA & CFC & SA & PI \\
\hline CS & 0.845 & & & & & & & & \\
EC & 0.077 & 0.669 & & & & & & & \\
MAP & 0.254 & 0.016 & 0.552 & & & & & & \\
OFA & 0.069 & 0.001 & 0.086 & 0.549 & & & & & \\
SMS & 0.268 & 0.060 & 0.031 & 0.007 & 0.577 & & & & \\
SDA & 0.286 & 0.001 & 0.244 & 0.033 & 0.038 & 0.599 & & & \\
CFC & 0.324 & 0.053 & 0.045 & 0.001 & 0.219 & 0.049 & 0.640 & & \\
SA & 0.349 & 0.004 & 0.148 & 0.028 & 0.171 & 0.142 & 0.212 & 0.736 & \\
PI & 0.280 & 0.136 & 0.019 & 0.004 & 0.067 & 0.067 & 0.078 & 0.005 & 0.685 \\
\hline
\end{tabular}

Structural model test

The test of fit model need to achieve the following criteria: The ratio of Chi-square and freedom degrees should be less than 3, Root mean square error of approximation (RMSEA) should be less than 0.05, Goodness of fit index (GFI), Incremental Fit Index (IFI), Tucker-Lewis Index (TLI) and Comparative Fit Index (CFI) should be more than 0.9. As seen from table 4, the model and data has good suitability.

Table 4. Structural model fitting

\begin{tabular}{ccccccc}
\hline Model & CMIN/DF & RMSEA & GFI & IFI & TLI & CFI \\
\hline Results & 1.402 & 0.041 & 0.897 & 0.971 & 0.964 & 0.970 \\
Fit Criteria & $\leq 3.0$ & $\leq 0.08$ & $\geq 0.8$ & $\geq 0.9$ & $\geq 0.9$ & $\geq 0.9$ \\
\hline
\end{tabular}

Regression results

The results from Table 5 show that H8,H6,H3,H7,H5,H1,H2 are accepted, while H4 is refused. From the standardized path coefficient, we can find that the impact of all kinds of factors on construction progress delay is different, and the estimated value range from 0.146 to 0.340 , and what influences the construction schedule delay largest is the policy imperfection factor(0.340), next are supervision unit ability factor (0.282), contractor fiscal capacity factor (0.191), survey and design unit ability 
factor (0.172), management ability factor of project management (0.148), owner fiscal capacity risk (0.146) and selection and management subcontractor risk (0.135).

Table 5. Regression results

\begin{tabular}{cccc}
\hline Hypothesis & Estimation & $\mathrm{P}$ & $\begin{array}{c}\text { Accept/ } \\
\text { Rejection }\end{array}$ \\
\hline H9 & 0.340 & $* * *$ & Accept \\
H7 & 0.282 & $* * *$ & Accept \\
H3 & 0.191 & $* * *$ & Accept \\
H8 & 0.172 & 0.001 & Accept \\
H6 & 0.135 & 0.009 & Accept \\
H1 & 0.146 & 0.001 & Accept \\
H2 & 0.148 & 0.007 & Accept \\
H4 & 0.070 & 0.149 & Rejection \\
\hline
\end{tabular}

$* * *$ expresses $p<0.001$

\section{Conclusion and Suggestion}

From the perspective of stakeholders, this paper summarizes potential influencing factors of construction delays in Vietnam highway construction from the related study, then empirical study is discussed through the questionnaire survey, and structural equation model is introduced into the influence of each risk factor for the comprehensive evaluation. The empirical results show that the influence degree of factors influencing the Vietnam highway construction delays is as follow: policy change, supervision unit ability, contractor fiscal capacity, survey and design unit ability, management ability of project management, owner fiscal ability, selection and management of subcontractor. About the special cases of highway construction in Vietnam, enterprises can take corresponding measures to avoid and reduce the risk of project delay when participating in Vietnam engineering construction.

(1) In the process of Vietnam 's engineering management mechanism transformation from national centralized management mechanism to union, which consisted of many components, management mechanism, policy changes, including land compensation policy will bring the difficulties in land requisition resulting to schedule delays and cost ascension. Change of infrastructure investment policy would make financing plan changes, some investors limited to participate in the projects and affect the financing of projects. The complex investment process and administrative procedures, bidding management policy is not perfect makes it difficult to be fair and open. So project participants should strengthen the research and forecast on relevant laws and regulations, standards, planning and policy to timely response to the potential risks brought by policy changes.

(2) Communication of contractors with owners, supervision, survey and design units should be strengthened. In construction process, contractors should guarantee that the construction funds will be in place timely. In project acceptance stage, accidents and slow acceptance should be dealt with project management and supervision units timely. In addition, the owners' land requisition will cause construction schedule delay and the construction cost increase in Vietnam, which is common, so the contractors should precise terms of handing over land requisition timely when signing a contract and be entirely responsible for loss caused by handing over land requisition untimely.

(3) Strengthen financial management. In bidding for a project, contractor should think carefully about their own capitals, loans and project operation risk to formulate reasonable bid amount; the contractor can work together with the bank, using the bank's own capital and credit to provide credit guarantee and investment risk management for himself. Through strengthening cooperation and 
integrating resources, enterprises employ the forms of joint bidding, try to avoid vicious price competition, and achieve a win-win situation.

(4) The contractor should not use the exploration data of engineering geological and hydrogeological blindly in construction process. Field investigation should be further strengthened to ensure a comprehensive and reliable basic data. Organize the relevant units, such as design engineer, engineering investigation and expert, strictly to cooperate in construction process.

(5) In Vietnam, the phenomenon of secondary subcontracting of contractor is very common and the subcontractor's poor ability has the serious influence on construction schedule. So it should be clear that evaluation index system of choosing subcontractor and the responsibility and authority of the contracting parties in the contract. The contractor should strengthen field management and timely coordination of subcontractor to ensure smooth implementation of project schedule.

\section{Conflict of Interest}

The authors confirm that this article content has no conflicts of interest.

\section{Acknowledgements}

This work was financially supported by National Natural Science Foundation of China (71271175), Youth Foundation Project of the Ministry of Education Research of Social Sciences (12YJC630096) and Soft Science Project of the Science and Technology Department of Sichuan(2014ZR0028).

\section{References}

[1] S.A. Assaf and S. Al-Hejji: INT J PROJ MANAG Vol.24(2006), p. 349

[2] W. Belassi and O.I. Tukel: INT J PROJ MANAG Vol.14(1996), p. 141

[3] P.X.W. Zou, G. Zhang and J.Wang:INT J PROJ MANAG Vol.25(2007), p. 601

[4] J.I. Alzahrani and M.W. Emsley: INT J PROJ MANAG Vol.31(2013), p. 313

[5] T. Zayed, Amer Mand and J. Pan: INT J PROJ MANAG Vol.26(2008), p. 408

[6] H. Subramanyan, P.H. Sawant and V.Bhatt: J CONSTR ENG M ASCE Vol.138(2012), p.409

[7] S.M. El-Sayegh and M.H. Mansour: J MANAGE ENG, Vol.31(2015).

[8] N.D.Long, S.Ogunlana, T.Quang and K.C.Lam: INT J PROJ MANAG Vol. 22(2004), p. 553

[9] L. Le-Hoai, Y. Dai Lee and J.Y. Lee: KSCE J CIV ENG Vol.12(2008), p. 367.

[10]C.H. Thi and F.W. Swierczek: ASIA PAC BUS REV Vol.16(2010), p. 567

[11]H. Abdul-Rahman, C. Wang, R. Takim and S. Wong: SCI RES ESSAYS Vol.6(2011): p. 205

[12]C. Kaliba, M. Muya and K. Mumba: INT J PROJ MANAG Vol.27(2009), p. 522 